\title{
Studies on Allelopathic Effect of Aqueous Leaf Extract of Putranjiva Roxburghii Wall. on Seed Germination and Early Growth of Chickpea (Cicer Arietinum L.)
}

\author{
Satyajit Oraon, Subrata Mondal
}

10.18805/IJARe.A-5319

\begin{abstract}
The present study reveals the allelopathic effect of aqueous leaf extracts of Putranjiva roxburghii Wall. on seed germination and early growth stages of an economically important plant chickpea (Cicer arietinum L.). Aqueous leaf extracts at $0,5,10,15,25,35,50,75$ and $100 \%$ concentrations were applied to determine their effect on seed germination and early growth stages under laboratory conditions. Laboratory-based experiments with three replicates were used to arrange treatments accordingly. After 5 days of incubation the rate of seed germination, radicle length and hypocotyls length etc. of chickpea seeds were observed after treatment with aqueous leaf extracts. Highest inhibitory effect was noticed in $100 \%$ of aqueous leaf extract. Results indicated that the inhibitory effect was proportional to the concentration of the extracts. The water soluble leaf extracts contain allelochemicals, which inhibit the seed germination and reduced the early growth of chickpea.
\end{abstract}

Key words: Allelopathic effect, Cicer arietinum L., Early growth stages, Putranjiva roxburghii wall., Seed germination.

\section{INTRODUCTION}

Allelopathy, has been defined as an adverse influence or interference of one plant or microorganism on another (Rice, 1974). Interference refers the overall effect of one plant upon another and encompasses both allelopathy and competition. Competition involves the removal or diminution of a shared resource, while allelopathy involves the addition of a chemical compound, which negatively or positively affect other neighboring plants in the environment through different processes (Putnam, 1985). It was found that allelopathy, has been involved in many natural and manipulated ecosystems and plays a key role in the evolution of plant communities, exotic plant invasion and plantation failure (Ridenour and Callaway, 2001). Allelopathic plant interactions can have either a harmful or beneficial effect and it was generally evaluated by testing some physiological mechanisms that results in the inhibition/stimulation of seed germination, plant growth and development due to the presence of another plant (Weston and Duke, 2003). The allelopathic effect on germination and growth of plants may occur through a variety of mechanisms including reduced mitotic activity in roots and hypocotyls, reduced rate of ion uptake, inhibited protein formation and decreased permeability of cell membranes (Rice, 1974). The production of chemical compounds by trees release into the ground vegetation under its canopy indicates that it has some allelopathic potentialities which might have caused either by fallen leaves or plant leachates or root exudates. Consequently, the release of allelochemicals into the soil inhibits seed germination and establishment of agricultural crops and vegetation (Rice, 1979). The easiest way to understand the ability of plants to inhibit or stimulate the
Department of Botany, Visva-Bharati, Santiniketan-731 235, West Bengal, India.

Corresponding Author: Subrata Mondal, Department of Botany, Visva-Bharati, Santiniketan-731 235, West Bengal, India.

Email: submondal@rediffmail.com

How to cite this article: Oraon, S. and Mondal, S. (2020). Studies on Allelopathic Effect of Aqueous Leaf Extract of Putranjiva Roxburghii Wall. on Seed Germination and Early Growth of Chickpea (Cicer Arietinum L.). Indian Journal of Agricultural Research. 54(2): 193-198.

Submitted: 24-06-2019 Accepted: 13-08-2019 Published: 09-11-2019 growth of other plants in an undisturbed environment is by observing the vegetation pattern of their canopies.

Putranjiva roxburghii Wall. (Euphorbiaceae) is an evergreen tree native to Southeast Asia and the Indian Subcontinent (Soltis and Soltis, 2004). It is also known for its medicinal properties and reported to be effective for infertility, fever, liver diseases and also it has properties such as anticancer, anti-inflammatory, antioxidant and diuretic. The leaves, fruits and stones of fruits are given as medicine in colds and fevers and also in rheumatic affections (Limbani et al., 2011). The plant has been selected because of high zone of inhibition on their surrounding vegetation, but no such works have been done regarding the allelopathic effect of aqueous leaf extracts of P.roxburghii.

Chickpea (Cicer arietinum L.), also known as Bengal gram and it is an important annual plant of the pea family (Fabaceae), widely grown in many countries for its nutritious seed value. Chickpeas are an economically important plant in India, Africa, and Central as well as South America (Lewis et al., 2005). It contains significant amount of essential 
proteins and vitamins which have a healthy benefits to the humans (Wallace et al., 2016). Moreover, they are becoming increasingly important as a source of raw material to food processing and value-added industrial products (Dry Pea and Lentil Council, 2015). The population pressure is a factor for highly demanding nutritious value of chickpea seeds in growing countries like India required more attention to be directed towards for its sustainable production (Dubey et al., 2017).

So, the purpose of the present study was to elucidate the allelopathic potential of different concentration of $P$. roxburghii aqueous leaf extracts on $C$. arietinum and such information will be beneficial for cultivation of chickpea.

\section{MATERIALS AND METHODS Plant materials}

As in flowering stage plant releases more allelochemicals than vegetative stage (Ahmed and Wardle, 1994), so fresh sample of leaves of $P$. roxburghii were collected during their flowering stages from different areas of Santiniketan $\left(23.68^{\circ} \mathrm{N} 87.68^{\circ} \mathrm{E}\right)$, Birbhum district, West Bengal, India. The plant twigs were brought into the laboratory and were immediately separated out the leaves. The fresh leaves were cut into 2-3 cm and washed several times with tap water. The leaves were shade dried at room temperature $\left(20-25^{\circ} \mathrm{C}\right)$ then grounded into powder with a mortar and pestle. Healthy uniform seeds of chickpea (C. arietinum L.) were obtained from Bidhan Chandra Krishi Viswavidyalaya (BCKV), Mohanpur, West Bengal, India. Before germination the chickpea seeds were surface sterilized with $4 \%$ sodium hypochloride for $5 \mathrm{~min}$ then rinsed with the distilled water for several times to remove excess chemicals (Jefferson and Pennacchio, 2003).

\section{Preparation of aqueous leaf extracts}

Dry leaf powder of $P$. roxburghii $(200 \mathrm{gm})$ was soaked for 24 hrs in $200 \mathrm{ml}$ double distilled water at room temperature $\left(20-22^{\circ} \mathrm{C}\right)$ in dark condition and the resultant solution was filtered through one layers of filter paper to remove debris and centrifuged at 3,000 rpm for $30 \mathrm{~min}$. The supernatant was then filtered through one layer Whatman no. 1 filter paper. The extracts used for bioassay were performed by diluting the stock solution (100\% w/v) at $75 \%, 50 \%, 35 \%$, 25\%, 15\%, 10\%, 5\% concentrations (Ashrafi et al. 2008; Yu et al. 2003). Adjustment of $\mathrm{pH}$ has been done at 6.5 with 1 (N) $\mathrm{NaOH}$ and $1(\mathrm{~N}) \mathrm{HCl}$ to avoid non-relevant effect of extracts due to $\mathrm{pH}$ (Uddin and Robinson, 2017).

\section{Seed bioassay}

Healthy and uniform seeds were selected and presoaked in distilled water for 2 hrs. Then 10 sterilized seeds were evenly placed on two layers of filter paper in each sterilized Petridish $(9 \mathrm{~cm})$. Seeds and filter papers were moistened with $10 \mathrm{ml}$ each of $5 \%, 10 \%, 15 \%, 25 \%, 35 \%, 50 \%, 75 \%$ and $100 \%$ of aqueous leaf extracts and $10 \mathrm{ml}$ of distilled water was added as control treatment. The Petridishes were placed in growth chamber $\left(25^{\circ} \mathrm{C}\right.$ and $70 \%$ relative humidity) as suggested by Mutlu and Atici (2009). Treatments were arranged in a completely randomized design (CRD) with three replicates. Seeds were considered germinated upon $2 \mathrm{~mm}$ of radicle emergence (Haugland and Brandsaeter, 1996) and germination was determined by counting the number of germinated seeds over a period of 5-days.

\section{Data collection and analysis}

The following parameters were studied during the experiment. Germination percentage of seeds was calculated following the formula:

germination percentage $(\%)=$

$$
\frac{\text { number of seeds germinated }}{\text { Total number of seeds }} \times 100
$$

The radicle and hypocotyls length of germinated seeds were measured by using centimeter ruler. After measuring the radicle and hypocotyl lengths, the seeds were separated into hypocotyl and radicle parts. After measuring the fresh weights (FW) of seeds then it was dried in hot air oven at $80^{\circ} \mathrm{C}$ and their respective dry weights (DW) were recorded. The relative water content was evaluated (Deef and $\mathrm{Rl}$, 2008) as

$$
\mathrm{RWC} \%=\frac{(\mathrm{FW}-\mathrm{DW} \times 100)}{\mathrm{FW}}
$$

For the calculation of percentage of inhibitory effect on seed germination, radicle length, hypocotyl length, fresh weight, dry weight, relative water content and seed vigour index, the following formula was used:

$$
I=100-\frac{E T \times 100}{E C}
$$

Where; I is the \% of inhibition, ET is the response of test plant and EC is the response of control plant (Surendra and Pota, 1978).

The seed vigour index (SVI) was calculated by the following formula; SVI = germination percentage $\times$ (shoot length + root length) as suggested by Abdul-Baki and Anderson (1973).

The data were analyzed statistically by ANOVA. Correlation coefficient was determined by data analysis from all treatments and the relation amongst seed growth parameters, relative water content and seed vigour index. Significance between control and treatment was compared at 0.05 probability levels.

\section{RESULTS AND DISCUSSION Germination percentage}

Putranjiva roxburghii leaf extracts showed differential influence on the seed germination and early growth of the chickpea. Among the different treatments, extracts of fresh leaves significantly reduced the early growth of Cicer arietinum seeds (Table 1 ). The reduction in the growth was 


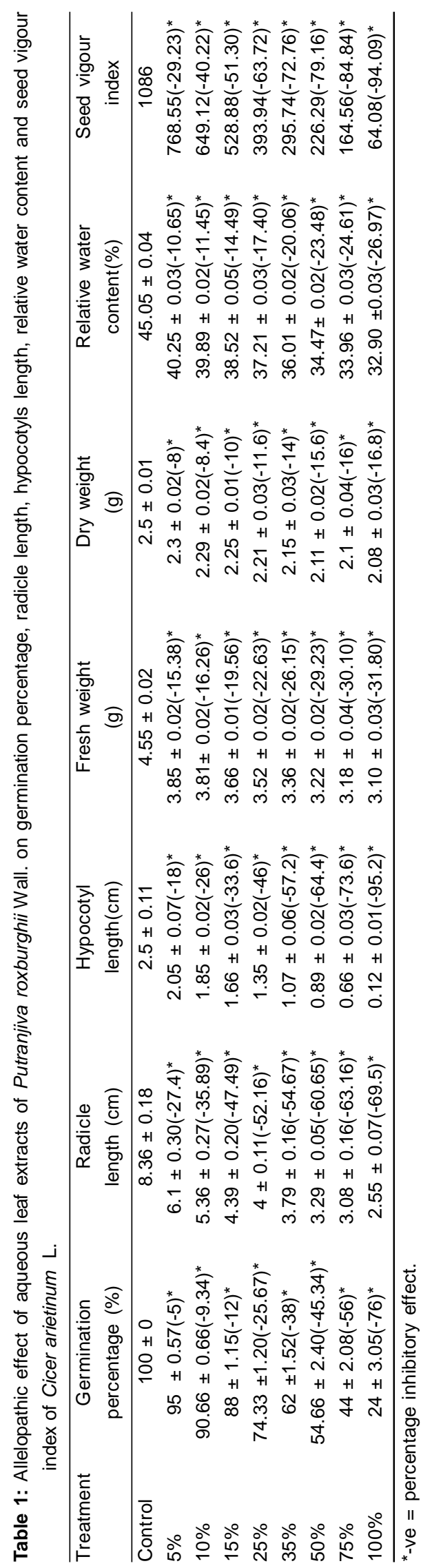

manifested in all the characters studied, viz. percentage of germination, radicle length, hypocotyls length, fresh weight, dry weight and relative water content as compared to that of control (Fig 2). The germination percentage decreased significantly to $95,90.66,88,74.33,62,54.66,44 \%$ at 5 , $10,15,25,35,50,75 \%$ aqueous leaf extracts respectively, while $24 \%$ seed germination was observed in $100 \%$ of aqueous leaf extracts whereas in control treatment, it showed $100 \%$ of germination. Higher concentrations viz., $75 \%$ and $100 \%$ aqueous leaf extracts showed high percentage of inhibition (-56 and -76 respectively) in germination. Similar observation of inhibitory effect at higher leaf extract concentrations on germination percentage has also been reported (Kaletha et al.,1996; Sahoo et al., 2010). It was well documented that allelo-chemicals suppress the mitotic activity of initially developed cells, resulting in the inhibition of seed germination (Rice, 1987). The results indicated that the variation on seed germination which agrees with Tefera (2002) who reported similar observation with Parthenium hysterophorus leaf on Eragrostis tef. seed.

\section{Growth parameters}

In most of the cases the growth parameters were varied evenly due to different percentage of aqueous leaf extracts concentrations, with the increase of concentrations the inhibitory effects were progressively increased. All leaf extracts concentrations viz., 5, 10, 15, 25, 35, 50, 75 and $100 \%$ of aqueous leaf extracts showed a inhibitory effect of $6.1,5.36,4.39,4,3.79,3.29,3.08,2.55 \mathrm{~cm}$ respectively on radicle length of Cicer arietinum $\mathrm{L}$. (Table 1 ). Radicle length was decreased significantly $(P<0.01)$ compared to the control with increasing concentrations of all aqueous leaf extracts. Radicle length of germinated seeds was highly sensitive to the allelochemicals. This may be due to the contact of the roots with the filter paper, leading to constant absorption of the different extract solutions (Sarkar et al., 2012). Earlier studies reported that aqueous leaf extracts of allelopathic plants had more sensitive effects on radicle growth than on hypocotyls growth or shoot (Turk and Tawaha, 2003).

All aqueous leaf extracts at all concentrations inhibited hypocotyls length compared with the control and the degree of inhibition increased with the increasing extract concentration. The highest inhibitory effect was observed on hypocotyls length $(0.12 \mathrm{~cm})$ at $100 \%$ of aqueous leaf extracts (Table 1). Such of an outcome might be expected from this result, because it is attributed that roots are the first to absorb the allelochemicals and then transfer it to their shoots.

The fresh weight (FW) and Dry weight (DW) of 5 days old chickpea seed were decreased significantly $(P<0.01)$ upon increasing treatment with the different concentrations of aqueous leaf extracts. The fresh weights were affected mostly than the dry weights at $75 \%$ and $100 \%$ leaf extracts. The same trends were also observed with regard to the percentage of relative water content (RWC) of seeds. The 


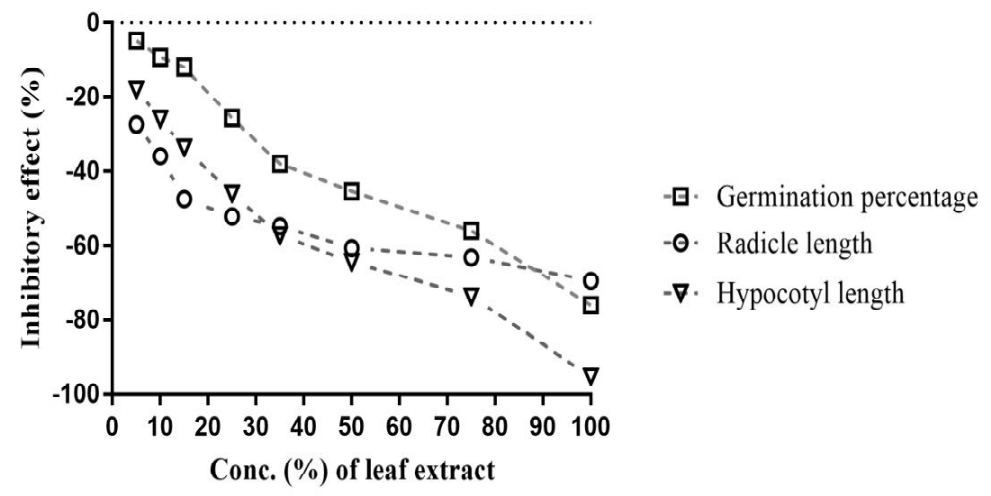

Fig 1: Percentage of inhibitory (-ve) effect treatments on germination percentage, radicle length and hypocotyl length after treatment with different concentrations of aqueous leaf extracts.

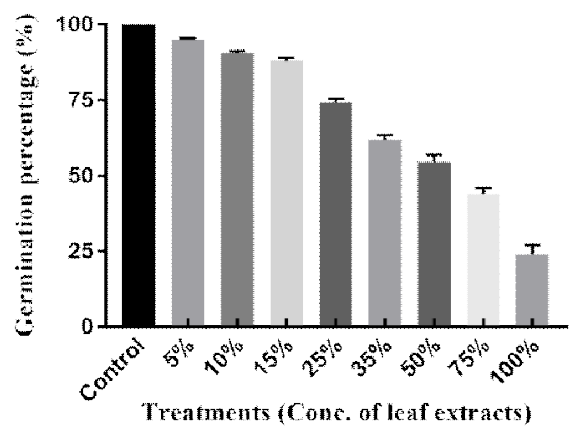

(A)

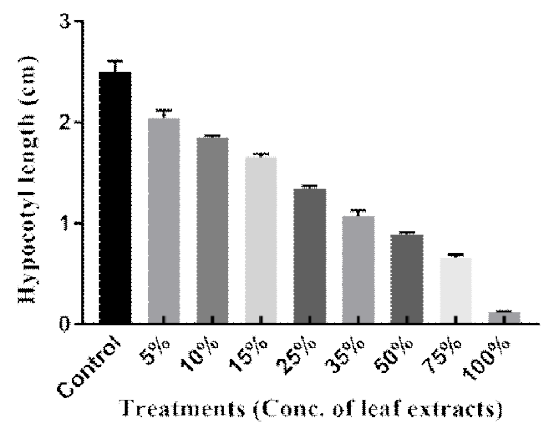

(C)

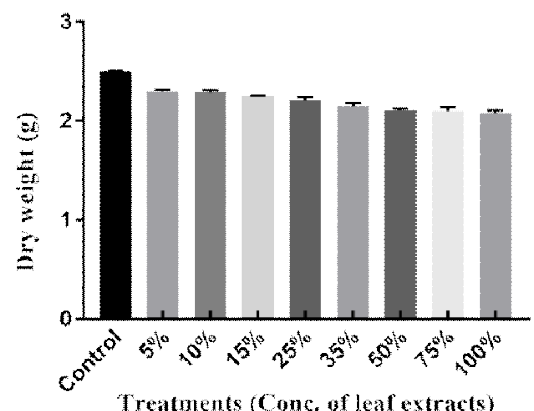

(E)

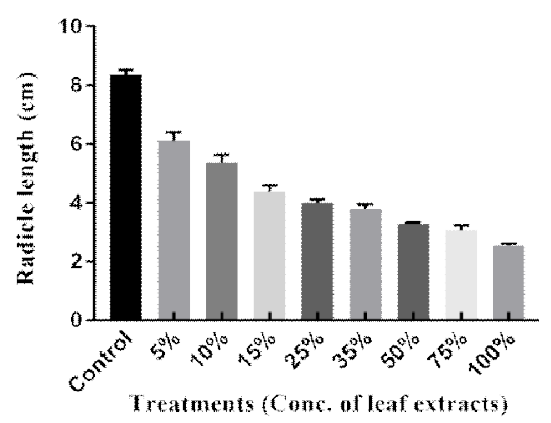

(B)

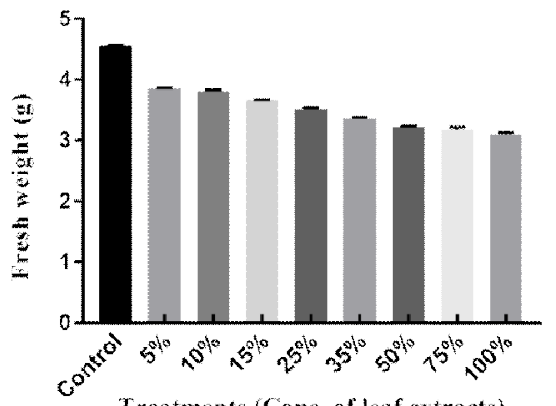

Treatments (Conc, of leaf extracts)

(D)

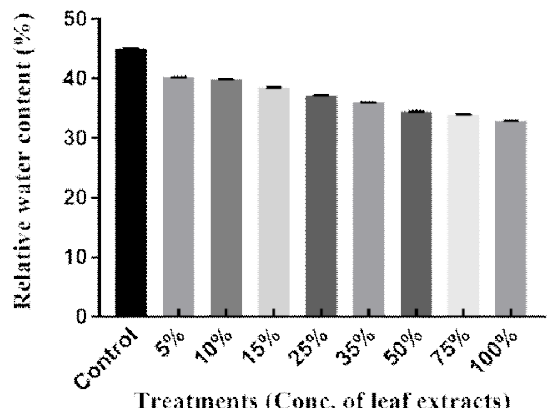

(F)

Fig 2 : The effect of different concentrations of aqueous leaf extracts $(0,5,10,15,25,35,50,75$, and $100 \%)$ of Putranjiva roxburghii on (A) Germination percentage, (B) Radicle length, (C) Hypocotyl length, (D) Fresh weight, (E) Dry weight, (F) Relative water content, after 5 days of incubation of chickpea seeds under laboratory conditions. Only one untreated control bar is used for all the different concentration levels. Vertical bars show standard error of mean of three replicates. 
Studies on Allelopathic Effect of Aqueous Leaf Extract of Putranjiva Roxburghii Wall. on Seed Germination and Early.....

RWC decreases significantly $(\mathrm{P}<0.001)$ when concentrations increased. Thus, it helped to understand that the inhibitory effect of allelochemicals in relation to the relative water content of seeds which was a key factor to evaluate seed germination and the correlation of relative water content and germination percentage showed highly significant value $(p<0.001)$. The similar observation was found in study of barley and wheat, the elongation and dry weight of seedlings were reported to be reduced by the walnut allelochemical juglone (Terzi and Kocacaliskan, 2010).

Seed vigour is an important parameter for checking the quality of seeds. From the standard germination test it is not easy to predict the field performance of seed as a result, scientists have emphasized the development of seed vigour index test (Usha and Dadlani, 2015). It was observed that $100 \%$ of leaf extract showed highly reduced seed vigour index which was 64.08 , whereas in control treatment the seed vigour index was 1086 . The seed vigour index also significantly $(P<0.001)$ decreased rapidly when the leaf extracts concentrations were increased. The leaf extracts showed higher inhibitory effect in higher concentrations on germination and all growth parameters of chickpea seed which showed inhibitory effect even in low concentrations (Fig 1; Table 1). The test for evaluating the seed vigour index was considered the important growth parameters like germination percentage, radicle length, hypocotyls length and all these parameters were significantly correlated $(P<0.001)$ with seed vigour index. The results showed as similar as to the result of Das et al. (2012) in seed vigour index. They studied the allelopathic effect of extracts of leaf litter of some selected tree species on gram seeds under laboratory conditions.

\section{CONCLUSION}

The inhibitory effect of leaf extracts of Putranjiva roxburghii has to be considered before recommending any species for agro forestry and the study focuses the complexity of allelopathic interactions on seed and seedling growth. Further work is needed to specify and isolate the allelochemicals produced by Putranjiva roxburghii.

\section{ACKNOWLEDGEMENT}

Authors are thankful to the UGC Non-NET fellowship for financial assistance and the Department of Botany (DSTFIST \& UGC-SAP, DRS) Visva-Bharati, for providing necessary laboratory facilities.

\section{REFERENCES}

Abdul-Baki, A.A. and Anderson, J.D. (1973). Vigor determination in soybean seed by multiple criteria. Crop science. 13(6): 630-633.

Ahmed, M. and Wardle, D.A. (1994). Allelopathic potential of vegetative and flowering ragwort (Senecio jacobaea L.) plants against associated pasture species. Plant and Soil. 164(1): 61-68.
Ashrafi, Z., Sadeghi, S, Mashhadi, H. and Hassan, M. (2008). Allelopathic effects of sunflower (Helianthus annuus) on germination and growth of wild barley (Hordeum spontaneum). Journal of Agricultural Technology. 4(1): 219-229.

Das, C., Mondal, N., Aditya, P., Datta, J., Banerjee, A. and Das, K. (2012). Allelopathic potentialities of leachates of leaf litter of some selected tree species on gram seeds under laboratory conditions. Asian Journal of Experimental Biological Sciences. 3(1): 59-65.

Deef, H.E. and Abd El-Fattah, R.I. (2008). Allelopathic effects of water extract of Artemisia princeps var. orientalis on wheat under two types of soils. Academic Journal of Plant Science. 1: 12-17.

DPLC/Dry Pea and Lentil Council, USA. (2015). Technical Manual -Chapter: 2 General Properties of Dry Peas, Lentils \& Chickpeas. http://www.usapulses.com/chapter-2 generalproperties.htm.

Dubey, S., Raghav, R.S. and Singh, P. (2017). Enhancement of productivity for chickpea (Cicer arietinum L.) through Front Line Demonstration in Farmers' Fields. Legume Research. 40(2): 335-337.

Haugland, E. and Brandsaeter, L.O. (1996). Experiments on bioassay sensitivity in the study of allelopathy. Journal of Chemical Ecology. 22(10): 1845-1859.

Jefferson, L.V. and Pennacchio, M. (2003). Allelopathic effects of foliage extracts from four Chenopodiaceae species on seed germination. Journal of Arid Environment. 55: 275-285.

Kaletha, M., Bhatt, B. and Todaria, N. (1996). Tree-crop interactions in traditional agroforestry systems of Garhwal Himalaya. 1. Phytotoxic effects of farm trees on food crops. Allelopathy Journal. 3(2): 247-250.

Lewis, G., Schrire, B., MacKinder, B. and Lock, M. (2005). Legumes of the World, Royal Botanic Gardens Kew.

Limbani, R.K., Bandhiya, H.M., Dedakia, A.S., Desai, T.R., Patel, V.L. and Pandya, D.J. (2011). Pharmacognostic and phytochemical evaluation of leaves of Putranjiva roxburghii. International Journal of Comprehensive Pharmacy. 2(11): 1-3.

Mutlu, S. and Atici, O. (2009). Allelopathic effect of Nepeta meyeri Benth. extracts on seed germination and seedling growth of some crop plants. Acta Physiologiae Plantarum. 31(1): 89-93.

Putnam, A.R. (1985). Weed allelopathy. Weed Physiology Reproduction and Ecophysiology, CRC Press. 1: 131-155.

Rice, E.L. (1974). Allelopathy. Academic Press ,New York, USA.

Rice, E.L. (1979). Allelopathy-an update. The Botanical Review. 45(1): 15-109.

Rice, E.L. (1987). Allelopathy: an overview, Allelochemicals: Role in Agriculture and Forestry. Chapter. 2: 8-22, ACS Publications.

Ridenour, W.M. and Callaway, R.M. (2001). The relative importance of allelopathy in interference: the effects of an invasive weed on a native bunchgrass. Oecologia. 126(3): 444-450.

Sahoo, U., Jeeceelee, L., Vanlalhriatpuia, K., Upadhyaya, K. and Lalremruati, J. (2010). Allellopathic effects of leaf leachate of Mangifera indica L. on initial growth parameters of few home garden food crops. World Applied Sciences Journal. 10(12): 1438-1447.

Sarkar, E., Chatterjee, S.N. and Chakraborty, P. (2012). Allelopathic effect of Cassia tora on seed germination and growth of 
Studies on Allelopathic Effect of Aqueous Leaf Extract of Putranjiva Roxburghii Wall. on Seed Germination and Early.....

mustard. Turkish Journal of Botany. 36(5): 488-494.

Soltis, P.S. and Soltis, D.E. (2004). The origin and diversification of angiosperms. American Journal of Botany. 91(10): 1614-1626.

Surendra, M. and Pota, K. (1978). On the allelopathic potentials of root exudates from different ages of Celosia argentea Linn. National Academy Science Letters. 1(2): 56-58.

Tefera, T. (2002). Allelopathic effects of Parthenium hysterophorus extracts on seed germination and seedling growth of Eragrostis tef. Journal of Agronomy and Crop Science. 188(5): 306-310.

Terzi, I. and Kocacaliskan, I. (2010). The effects of gibberellic acid and kinetin on overcoming the effects of juglone stress on seed germination and seedling growth. Turkish Journal of Botany. 34(2): 67-72.

Turk, M.A. and Tawaha, A.M. (2003). Allelopathic effect of black masturd (Brassica nigra L.) on germination and growth of wild oat (Avena fatua L.). Crop Protection. 22: 673677.

Uddin, M.N. and Robinson, R.W. (2017). Allelopathy and resource competition: the effects of Phragmites australis invasion in plant communities. Botanical Studies. 58(1): 29.

Usha, T.N. and Dadlani, M. (2015). Evaluation of seed vigour in soyabean (Glycine max). Legume Research. 38(3): 308-312.

Wallace, T.C., Murray, R. and Zelman, K.M. (2016). The nutritional value and health benefits of chickpeas and hummus. Nutrients. 8(12): 766.

Weston, L.A. and Duke, S.O. (2003). Weed and crop allelopathy. Critical Reviews in Plant Sciences. 22(3-4): 367-389.

Yu, J.Q., Ye, S.F., Zhang, M.F. and Hu, W.H. (2003). Effects of root exudates and aqueous root extracts of cucumber (Cucumis sativus) and allelochemicals, on photosynthesis and antioxidant enzymes in cucumber. Biochemical Systematics and Ecology. 31(2): 129-139. 